\title{
Rejoinder to \\ Perspectival representation in DSGE models by Paweł Kawalec
}

\author{
Marcin Kolasa ${ }^{1}$
}

All dominant paradigms attract criticism. Therefore, it comes as no surprise that, after DSGE models emerged as a workhorse tool for macroeconomic analysis in both academic and policy-making circles, their assumptions and implications have met (sometimes severe) opposition. This kind of discussion is usually healthy, especially when it involves well-established scholars who have a good understanding of the mainstream literature. The critique usually comes in two genres. If expressed by insiders (e.g. Blanchard, 2016), it usually calls for refinement of the existing framework, without a heavy damage to its core, and the chances that the proposed ideas will make some impact are high. In contrast, attacks launched from the outside usually dismiss the founding concepts and, especially if no clear alternative is offered, tend to instigate shortlived outrage from their supporters, but then are largely ignored.

The critique of Romer (2016) is of the second type. It is also packed with attacks that look personal or even insulting to his opponents, suggesting i.a. that they are involved in some form of unfair collusion that puts personal interest or group loyalty before progress of science. Therefore, it is tempting to dump it altogether, which would be wrong, given that some points raised by Romer are serious and deserve a deeper thought. This is why I think that the defense of DSGE models offered by Paweł Kawalec, who concentrates on philosophical lines of Romer's critique, is very useful and worth reading.

In this short rejoinder I am going to share my own views on the current stance and prospects for DSGE models, drawing from my experience as a researcher and central bank economist. It is useful to start from a proposition that DSGE models are a compromise between rigorous academic research and policy makers' pragmatism. The former favors relatively small models, where key mechanisms can be clearly understood. The structure ideally includes only those ingredients that are necessary for exposing these mechanisms, and its

\footnotetext{
${ }^{1}$ Warsaw School of Economics, Department of Quantitative Economics, ul. Madalińskiego 6/8, 02-513 Warszawa, Poland and Narodowy Bank Polski, marcin.kolasa@sgh.waw.pl.
} 
validation uses only a narrow set of data that the model seeks to explain. It very often does not make sense to apply such models to address questions that are too distant from the ones originally asked. In other words, academic models are usually quite specialized, even in macroeconomic applications, and despite the fact that their very core, consisting of a description of household preferences or production technology, might be highly standardized.

To inform the policymakers, small and tailored models can also be very useful as they help understand the workings of particular mechanisms. However, policy-making institutions such as central banks also need models that they can use regularly to communicate their views on the whole economy, and which can be readily applied to deliver guidance on macroeconomic consequences of some expected or unexpected changes in the economic environment. Therefore, these models must be relatively large, and hence more difficult to grasp, operate and control. Moreover, they should have a possibly large degree of theoretical coherence, be relatively sparsely and deeply parametrized so that the Lucas critique does not immediately apply, and at the same time have decent data fit and forecasting properties as central banks usually publish their macroeconomic forecasts.

It is clear that meeting simultaneously all of these criteria to a degree that could be considered satisfactory is extremely hard, if possible at all. Hence, the ultimate modelling framework of choice depends on the user's preferences about how the tradeoff between macroeconomic theory and data should be resolved, and is inherently vulnerable to criticism, especially from the extreme wings, either for insufficient theoretical purity, or too poor coherence with empirical evidence.

What is crucial, however, is whether the model is at the frontier of 'bestpractice' for a given mix of empirical and theoretical coherence (Pagan, 2003). I think that modern DSGE models are at this frontier. They can be considered reasonably structural, even though they do feature shocks that can be considered imaginary and which simply mask model misspecification rather than corresponding to real forces driving the economy. They are also competitive in forecasting, not only with time series models, but with professional forecasters (Del Negro \& Schorfheide, 2013).

Naturally, this frontier is not static, but is continually shifting outwards, and I share the optimism of Blanchard (2016) that there is vast room for improvement of DSGE models. However, my optimism is not uniformly spread over all of the aspects that are relevant to policy makers. In particular, I do not believe that really large gains in forecast accuracy can be obtained in the near future, if ever. This skepticism is not restricted to DSGE models, for which it has been shown that a richer structure does not necessarily lead to better forecasts (see e.g. Kolasa \& Rubaszek, 2016), but applies to macroeconomic forecasting more generally, and in particular the disappointing performance of non-linear models (Terasvirta, 2006). At the same time, I do believe that some core ingredients 
of DSGE models can be replaced with better ones relatively soon. One example is the currently dominant description of household behavior that excessively concentrates on intertemporal motives, which is in contrast to empirical evidence and findings from fast developing class of heterogeneous agent models.

Finally, let me say that I do not share Romer's concern that progress in macroeconomics is significantly inhibited by excessive deference to authorities or ill-defined group loyalty. I think that the right incentives are there, and innovative research that offers genuine improvement or an alternative to the currently dominant DSGE framework is highly welcome, in many academic circles, and probably even more in policy-making institutions.

\section{References}

Blanchard, O. (2016). Do DSGE models have a future? Policy Brief, No. 16-11. Peterson Institute of International Economics.

Del Negro, M., \& Schorfheide, F. (2013). DSGE model-based forecasting. In: G., Elliott, C., Granger, \& A. Timmermann (Eds.), Handbook of Economic Forecasting, 2(2), 57-140. Elsevier.

Kolasa, M., \& Rubaszek, M. (2016). Does foreign sector help forecast domestic variables in DSGE models? KAE Working Paper, No. 2016-022, Warsaw School of Economics.

Pagan, A. (2003). Report on modelling and forecasting at the Bank of England. Bank of England Quarterly Bulletin, Spring, 60-88.

Romer, P. (2016). The Trouble with macroeconomics. The American Economist (forthcoming).

Terasvirta, T. (2006). Forecasting economic variables with nonlinear models. In: G., Elliott, C., Granger, \& A. Timmermann (Eds.), Handbook of Economic Forecasting, 1(1), 413-457. Elsevier. 